\title{
A general two-phase turbulent flow model applied to the study of sediment transport in open channels
}

\author{
Xin Chen ${ }^{a}$, Yong Li ${ }^{b}$, Xiaojing Niu ${ }^{a}$, Ming $\mathrm{Li}^{\mathrm{c}}$, Daoyi Chen ${ }^{\mathrm{c}}$, Xiping $\mathrm{Yu}^{\mathrm{a}, *}$ \\ a State Key Laboratory of Hydroscience and Engineering, Department of Hydraulic Engineering, Tsinghua University, Beijing, China \\ ${ }^{\mathrm{b}}$ Institute of Mechanics, Chinese Academy of Science, Beijing, China \\ 'School of Engineering, University of Liverpool, Liverpool, UK
}

\section{A R T I C L E I N F O}

\section{Article history:}

Received 13 February 2011

Received in revised form 19 May 2011

Accepted 21 May 2011

Available online 30 May 2011

\section{Keywords:}

Two-phase flow

Sediment transport

Numerical model

Model verification

\begin{abstract}
A B S T R A C T
A numerical model for the general description of the sediment-laden flow is developed based on an Euler-Euler approach of the two-phase turbulent flow theory. The basic equations of the model are the Reynolds averaged equations of motion for both the fluid and the sediment phase in addition to the Reynolds averaged continuity equations for the mixture and for the sediment phase. The fluid phase and the sediment phase are coupled through their interaction forces including resistance force, inertia force, and lift force. Turbulence closure of the fluid phase is based on the conventional $k-\varepsilon$ model while an algebraic particle turbulence model is applied to the sediment phase. The numerical method is based on the modified SIMPLE scheme. The model is applied to the computation of saturated sediment-laden flows and also the non-equilibrium transport of sediment by unidirectional flows under simple erosion and simple deposition conditions. The numerical results are well verified by the available experimental data. The vertical velocity of the sediment phase is also shown to be in very good agreement with the fall velocity of the sediment particles, which strongly support the assumption of Rouse's diffusion theory for suspended sediment under steady state.
\end{abstract}

(c) 2011 Elsevier Ltd. All rights reserved.

\section{Introduction}

The mechanics of sediment transport is an important subject of river and coastal engineering. Traditionally, this is because the erosion and deposition as the result of sediment movement are, in many cases, critical to the safety, the functional performance, and the environmental impact of a river or coastal engineering project. More recently, the significance of the sediment transport in river and coastal zone management has also been emphasized because the habitat for fish and other organisms, and consequently, the river and coastal ecosystem may be unfavorably altered or even damaged due to unexpected sediment movement.

The mechanics of sediment transport is also a classical subject of river and coastal engineering, and its study can be traced to 1930s. The earlier studies, however, were essentially empirical. By the empirical or semi-empirical formulas carefully developed, the critical condition for the initial motion of sediment as well as the rate of sediment transport can be fairly reasonably predicted once the flow condition is given. The vertical distribution of the sediment concentration in a steady channel flow can also be simulated at very good accuracy.

There is no question that the sediment-laden flow can be treated as essentially a two-phase flow. The most orthodox approach

\footnotetext{
* Corresponding author.

E-mail address: yuxiping@tsinghua.edu.cn (X. Yu).
}

to the problem, from the mechanics point of view, is thus to start from the conservation laws for both the fluid and the sediments, i.e., the continuity equation and the equations of motion for both the water and the sediment. In fact, a large number of researches have been devoted to the development and application of such two-phase flow models. These models can be categorized into the Euler-Lagrange type and the Euler-Euler type. The EulerLagrange approaches describe the water or the continuous phase by mass and momentum conservation equations while the sediment or the dispersed phase by the equation of motion for each particle. When the flow involves a large number of sediment particles, a statistical description of the dispersed phase may become necessary in order to reduce the computational efforts. Since a practical problem usually includes an enormous number of sediment particles, more previous efforts have actually been directed to the development and enhancement of the Euler-Euler approaches (Drew, 1971, 1983; Elghobashi and Abou-Arab, 1983; Ishii and Hibiki, 2006), which describe the dispersed phase in the similar way as for the continuous phase.

Since a two-phase flow model is usually difficult to be solved even numerically, there have been intensive efforts to simplify the problem based on various assumptions. The so-called single phase model, which deals with the two phases as a whole, or the mixture, instead of the two phases separately, is an example of the simplified models (Zuber and Findlay, 1965; Celik and Rodi, 1988; Pai, 1991; Ungarish, 1993). Among a variety of the single phase models, the 
advection-diffusion model, which further neglects the effects of the dispersed phase on the continuous phase and is, therefore, valid only for dilute problems, has been preferred by many researchers who bear obligation to provide solutions for practical problems.

It has long been an expectation of engineers to study the sediment transport in river and in coastal waters, particularly the transport of suspended load, based on an effective two-phase flow model. But, the progress has been rather slow, probably because the problem is too complicated. Most of the research efforts done are still limited to proposal of mathematical models. Some suggestions to study the distribution of sediment concentration and rate of transport under steady state based on a two-phase flow model were made (McTigue, 1981; Kobayashi and Seo, 1985; Cao et al., 1995; Greimann and Holly, 2001), but none of the authors provided a model with sufficient generality. Other models were formulated in a relatively general form, but only applied to the one dimensional situations (Jha and Bombardelli, 2010). Bakhtyar et al. (2009) developed a rather comprehensive model but the model did not consider the turbulent fluctuation of the volumetrically averaged concentration and thus includes no diffusion terms in the continuity equations. Longo's (2005) model took into account all the major factors partially considered in many other models, but its verification is far from convincing. It may be worthwhile to stress that an important but difficult point in the formulation of a two-phase flow model is to properly describe the turbulence characteristics of the two phases. Recently, Jha and Bombardelli (2009) comparatively investigated the performance of different turbulence models for the continuous phase, while Hsu et al. (2004) paid attention to the turbulence modeling of the sediment phase.

In river and coastal engineering applications, the most practical model for the sediment laden flows is still the advection-diffusion model, if the empirical and semi-empirical models are not the choice. The model has been proposed since 1930s (O'Brien, 1933; Dobbins, 1943). Successful applications to practical problems in which suspended sediment transport is predominant have been widely reported after 1980s (Lin et al., 1983; Miller, 1983; Zhou and Lin, 1998; Wu et al., 2000; Chapalain and Thais, 2000; Fang and Wang, 2000; Douillet et al., 2001). At the same time, the intrinsic limitations of the advection-diffusion model have also been pointed out frequently. More critically, the model provides no way to deal with the bed load transport, which often plays dominant role in practice.

The present work is aimed to develop a general numerical model for steady sediment transport by a vertically two-dimensional flow based on the two-phase turbulent flow theory. We try to carefully deal with the turbulence model, the inter-granular stress, and the interphase forces so that the model can represent both the suspended load and the bed load. Such a model can also describe the sediment pick-up/settle-down process. Therefore, the conventional practice relying on the empirical formulas to give the sediment concentration at a particular level or specify the pick-up rate as a function of the flow parameters at the bottom boundary becomes unnecessary. The details of the model are shown in Section 2. Verifications of the model by comparing the computational results with experimental data and analytical solutions are given in Sections 3 and 4 for equilibrium and non-equilibrium transport, respectively. Conclusions are finally summarized in Section 5.

\section{Numerical model}

\subsection{Governing equations}

When the two-fluid approach, i.e., the Euler-Euler approach is adopted, the governing equations for each phase as well as the mixture of the sediment-laden flow can be obtained based on the Reynolds averaging procedure. It is evident that these equations are not all independent. The Reynolds averaged continuity equations for the mixture and for the sediment phase, the Reynolds averaged equations of motion for both the fluid and the sediment phase, in addition to the simple algebraic relation between the volumetric concentration of the fluid and that of the sediment, which form an independent set, are chosen as the basic equations in the present study. So, we have

$$
\begin{aligned}
& \frac{\partial \alpha_{f} u_{f, j}}{\partial x_{j}}+\frac{\partial \alpha_{s} u_{s, j}}{\partial x_{j}}=0 \\
& \frac{\partial \alpha_{s}}{\partial t}+\frac{\partial \alpha_{s} u_{s, j}}{\partial x_{j}}=\frac{\partial}{\partial x_{j}}\left(\kappa \frac{\partial \alpha_{s}}{\partial x_{j}}\right)
\end{aligned}
$$

$$
\begin{aligned}
\frac{\partial\left(\alpha_{f} u_{f, i}\right)}{\partial t}+\frac{\partial\left(\alpha_{f} u_{f, i} u_{f, j}\right)}{\partial x_{j}}= & -\frac{\alpha_{f}}{\rho_{f}} \frac{\partial p}{\partial x_{i}}+\frac{\partial}{\partial x_{j}}\left[\alpha_{f} v_{f}\left(\frac{\partial u_{f, i}}{\partial x_{j}}+\frac{\partial u_{f, j}}{\partial x_{i}}\right)\right]+\alpha_{f} g_{f, i} \\
& +\frac{\partial}{\partial x_{j}}\left[\kappa\left(u_{f, i} \frac{\partial \alpha_{f}}{\partial x_{j}}+u_{f, j} \frac{\partial \alpha_{f}}{\partial x_{i}}\right)\right]+\frac{F_{f, i}}{\rho_{f}} \\
\frac{\partial\left(\alpha_{s} u_{s, i}\right)}{\partial t}+\frac{\partial\left(\alpha_{s} u_{s, i} u_{s, j}\right)}{\partial x_{j}}= & -\frac{\alpha_{s}}{\rho_{s}} \frac{\partial p}{\partial x_{i}}+\frac{\partial}{\partial x_{j}}\left[\alpha_{s} v_{s}\left(\frac{\partial u_{s, i}}{\partial x_{j}}+\frac{\partial u_{s, j}}{\partial x_{i}}\right)\right]+\alpha_{s} g_{s, i} \\
& +\frac{\partial}{\partial x_{j}}\left[\kappa\left(u_{s, i} \frac{\partial \alpha_{s}}{\partial x_{j}}+u_{s, j} \frac{\partial \alpha_{s}}{\partial x_{i}}\right)\right]+\frac{F_{s, i}}{\rho_{s}}
\end{aligned}
$$

$\alpha_{f}+\alpha_{s}=1$

where the subscripts $f$ and $s$ denote the fluid phase and the sediment phase, respectively; $\alpha$ is the volumetric concentration; $u$ is the velocity; $p$ is the pressure; $F$ is the interaction force between the two phases; $g$ is the body force; $\rho$ is the density; $v$ is the viscosity; $x$ is the Cartesian coordinate; $t$ is time; the indices $i, j=1,2$ represent the coordinate directions and are required to follow the summation convention. Eqs. (1)-(5) form a closed system for $u_{f}$, $u_{s}, p, \alpha_{f}$, and $\alpha_{s}$. It may be worthwhile to mention that the volumetric concentrations, which are spatially averaged over a dimension much larger than the mean distance between sediment particles, are also assumed to be turbulent variables in the present model, and can thus be decomposed into a mean value and a turbulent fluctuation. Reynolds averaging then yields a mass diffusion term in Eqs. (2)-(4) after turbulence modeling:

$\overline{\alpha^{\prime} u_{i}^{\prime}}=-\kappa \frac{\partial \alpha}{\partial x_{i}}$

where the primes denote the turbulent fluctuation of the relevant quantities, the diffusion coefficient $\kappa$ is related to the eddy viscosity $v_{t}$ through $\kappa=v_{t} / \delta_{\alpha}$ with $\delta_{\alpha}$ being the Schmidt number. In addition, the eddy viscosity representation has been adopted for turbulence induced momentum diffusion.

The viscosities of the two phases are expressed by $v_{f}=v_{f 0}+v_{f t}$ and $v_{s}=v_{s 0}+v_{s t}$, respectively, where $v_{f 0}$ is the molecular viscosity of the fluid, $v_{f t}$ is the eddy viscosity of the fluid phase, $v_{s 0}$ is the viscosity related to the inter-granular stress, and $v_{s t}$ is the sediment turbulence viscosity. $v_{f t}$ and $v_{s t}$ are determined by turbulence modeling of the fluid phase and the sediment phase, respectively. The viscosity related to the inter-granular stress may be evaluated based on Ahilan and Sleath (1987) formula:

$v_{s 0}=1.2 \frac{\rho_{f}}{\rho_{s}}\left[\left(\frac{\alpha_{s m}}{\alpha_{s}}\right)^{1 / 3}-1\right]^{-2} v_{f 0}$

where $\alpha_{s m}$ is the maximum sediment volumetric concentration (it is assumed to be 0.6 in the present study). 
The interaction force between the sediment and the fluid phases satisfies the relation:

$\mathbf{F}_{f}+\mathbf{F}_{s}=0$

where the bold face represents a vector. We consider the dominant forces, i.e., the drag force, the inertia force, and the lift force in the present study. Let

$\mathbf{F}_{S}=\mathbf{F}_{D}+\mathbf{F}_{I}+\mathbf{F}_{L}$

The drag force $\mathbf{F}_{D}$ is expressed by

$\mathbf{F}_{D}=\lambda C_{D} \frac{3 \rho_{f} \alpha_{s}}{4 D_{s}}\left|\mathbf{u}_{f}-\mathbf{u}_{s}\right|\left(\mathbf{u}_{f}-\mathbf{u}_{s}\right)$

where $\mathbf{u}$ is the velocity vector, $D_{S}$ is the representative diameter of the sediment particles, $C_{D}$ is the drag coefficient of the particle in infinite fluid and $\lambda$ is a modification factor considering the effect of the surrounding particles. The drag coefficient $C_{D}$ is given by the well known Schiller and Naumann (1935) formula:

$C_{D}=\frac{24}{\operatorname{Re}_{s}}\left(1.0+0.15 \operatorname{Re}_{s}^{0.687}\right)$

where $\operatorname{Re}_{s}=\left|\mathbf{u}_{f}-\mathbf{u}_{s}\right| D_{s} / v_{f 0}$ is the particle Reynolds number. It may have to be noted that Eq. (11) is valid only when $\mathrm{Re}_{s} \leqslant 1000$. Beyond this range, $C_{D}$ becomes nearly a constant of 0.44 (Wörner, 2003) as long as the flow around the particle is laminar. Other choice of the drag coefficient formula is also possible (Peker and Helvaci, 2008) but an alternative does not seem to yield a significant difference on the results of sediment transport. The modification factor $\lambda$ in Eq. (10), which is related to the sediment concentration, follows Tam (1969):

$\lambda=\frac{4+3\left(8 \alpha_{s}-3 \alpha_{s}^{2}\right)^{0.5}+3 \alpha_{s}}{\left(2-3 \alpha_{s}\right)^{2}}$

In the present study, the inertia force and the lift force are expressed, respectively, by

$\mathbf{F}_{I}=C_{M} \rho_{f} \alpha_{s} \frac{d\left(\mathbf{u}_{f}-\mathbf{u}_{s}\right)}{d t}$

$\mathbf{F}_{L}=C_{L} \rho_{f} \alpha_{s}\left(\mathbf{u}_{f}-\mathbf{u}_{s}\right) \times \Omega$

where $\Omega$ is the vorticity vector of the fluid phase, $C_{M}=0.5$ is the added-mass coefficient and $C_{L}=0.5$ is the lift coefficient (Auton, 1987; Auton et al., 1988).

\subsection{Turbulence model}

The standard $k-\varepsilon$ model is used for turbulence modeling of the fluid phase in the present study, so the turbulence kinetic energy $k$ and the kinetic energy dissipation rate $\varepsilon$ of the fluid phase are governed by

$$
\begin{aligned}
& \frac{\partial\left(\alpha_{f} k_{f}\right)}{\partial t}+\frac{\partial\left(\alpha_{f} k_{f} u_{f j}\right)}{\partial x_{j}}=\frac{\partial}{\partial x_{j}}\left(\alpha_{f} v_{f k} \frac{\partial k_{f}}{\partial x_{j}}\right)+\alpha_{f}\left(G_{f}-\varepsilon_{f}\right) \\
& \frac{\partial\left(\alpha_{f} \varepsilon_{f}\right)}{\partial t}+\frac{\partial\left(\alpha_{f} \varepsilon_{f} u_{f j}\right)}{\partial x_{j}}=\frac{\partial}{\partial x_{j}}\left(\alpha_{f} v_{f \varepsilon} \frac{\partial \varepsilon_{f}}{\partial x_{j}}\right)+\frac{\alpha_{f}}{k_{f}}\left(C_{1} G_{f} \varepsilon_{f}-C_{2} \varepsilon_{f}^{2}\right)
\end{aligned}
$$

where

$v_{f k}=\frac{v_{f t}}{\delta_{k}}$

$v_{f \varepsilon}=\frac{v_{f t}}{\delta_{\varepsilon}}$

$v_{f t}=C_{\mu} \frac{k_{f}^{2}}{\varepsilon_{f}}$
$G_{f}=v_{f t} \frac{\partial u_{f, i}}{\partial x_{j}}\left(\frac{\partial u_{f, i}}{\partial x_{j}}+\frac{\partial u_{f, j}}{\partial x_{i}}\right)$

For the sediment phase, as far as the turbulence is not extremely anisotropic and the size of the sediment particle is reasonably small, Hinze-Tchen's algebraic particle turbulence model is applicable (Hinze, 1975):

$\frac{v_{s t}}{v_{f t}}=\sqrt{\frac{k_{s}}{k_{f}}}=\left(1+\frac{\tau_{s}}{\tau_{f}}\right)^{-1}$

where $\tau_{f}$ is the turbulence time scale of the fluid phase, $\tau_{s}$ is the response time of the sediment phase, and

$\tau_{f}=1.22 C_{\mu}^{3 / 4} \frac{k_{f}}{\varepsilon_{f}}$

$\tau_{s}=\frac{\rho_{s} D_{s}^{2}}{18 \rho_{f} v_{f 0}\left(1+0.15 \operatorname{Re}_{s}^{0.687}\right)}$

The Hinze-Tchen model requires that the sediment turbulence follows the fluid turbulence with a response time. The intensity of the sediment turbulence decreases as the response time of the sediment particles increases and the turbulence time scale decreases, and vice versa.

In the present study, all the empirical constants that appear in the turbulence model take the standard values except for the sediment Schmidt number $\delta_{\alpha}$, which tends to take a value smaller than 1.0 according to Jha and Bombardelli (2009) and is assumed to be 0.7 in the present study.

It must be pointed out that the interactions among particles within the bed load layer or a hyper-concentrated layer near the bed are intensive and highly nonlinear, which add significant influences to the characteristics of the sediment turbulence. The present model can be used but cannot be impractically expected to accurately represent the turbulence viscosity either of the sediment phase or of the fluid phase on such an occasion. In fact, no existing model has such a capacity. Fortunately, the sediment motion within a hyper-concentrated layer is mainly governed by the inter-granular stress instead of the turbulence diffusion, which implies that the validity of the two-phase model will not be significantly damaged.

\subsection{Numerical schemes}

The numerical method used in the present study is the modified SIMPLE scheme of Patankar (1980). Following this scheme, the governing equations for the sediment-laden flow are discretized into algebraic equations in terms of the nodal values of the physical quantities defined over a staggered grid, by means of the finite volume method. In addition, the third-order QUICK scheme of Tao (2001) is used for the convection terms, and the second-order central difference scheme used for the diffusion terms. The deferred correction technique of Hayase et al. (1992) is also adopted.

The time stepping strategy is standard. At each time step, the volumetric concentration of each phase is computed first. Then, the velocities of each phase are predicted and correction of the pressure is carried out based on the solution of the pressure correction equation derived from the overall mass conservation equation. The values of the pressure and the velocities can therefore be updated to satisfy mass and momentum conservation. If necessary, correction of the pressure and the velocity can be repeated to yield converged values being used as the initial conditions of the next step. The convergence is judged by the residuals of volume flux in the pressure modification equation. It is worthwhile to emphasize that the pressure modification in the present study is based on the total continuity equation instead of the continuity equation for 
each phase to ensure a better accuracy of mass conservation. This is because the continuity equation for each phase includes a diffusion term modeling the turbulent effect while discretization of the diffusion term adds errors in the numerical algorithm of the continuity equation. Once the volumetric concentration and the velocity of each phase are determined, the turbulence kinetic energy and the turbulence kinetic energy dissipation rate can be readily obtained. The interphase-slip algorithm (IPSA) of Spalding (1985) is used to deal with phase coupling. The stability conditions (O'Connor and Nicholson, 1988) should also be satisfied.

\subsection{Boundary conditions}

In the present study, three representative cases are considered: (i) equilibrium transport; (ii) simple erosion, the flow develops with the increase of sediment along the flow direction; (iii) simple deposition, as shown in Fig. 1. In all cases, the numerical model is applied to the entire sediment-laden flow covering both the bed load layer and the suspended load layer, although its accuracy for the bed load transport is certainly not comparable with the suspended load.

In all cases, the so-called 'rigid-lid' assumption is adopted at the top boundary. That is, the vertical velocity of the fluid phase at the top boundary vanishes, and all other variables satisfy the non-gradient condition in its normal direction, with an exception of the sediment concentration, which is governed by the zero-flux condition:

$\kappa \frac{\partial \alpha_{s}}{\partial x_{2}}-u_{s, 2} \alpha_{s}=0$

At the bottom boundary, which is set at the lower edge of the bed load layer, non-slip wall condition is applied to the fluid phase. In cases (i) and (ii), the vertical and horizontal velocities of the sed-

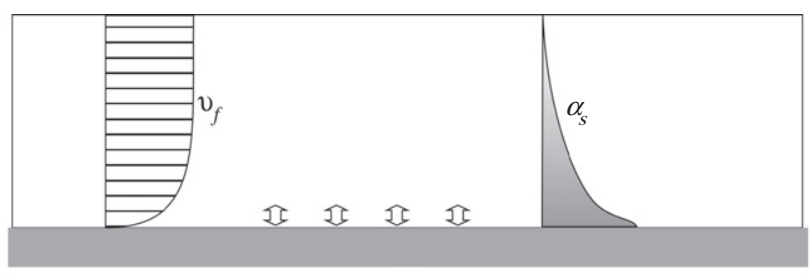

(a) Equilibrium case

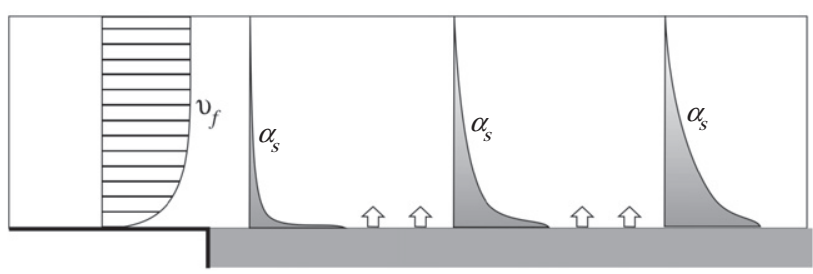

(b) Simple erosion case

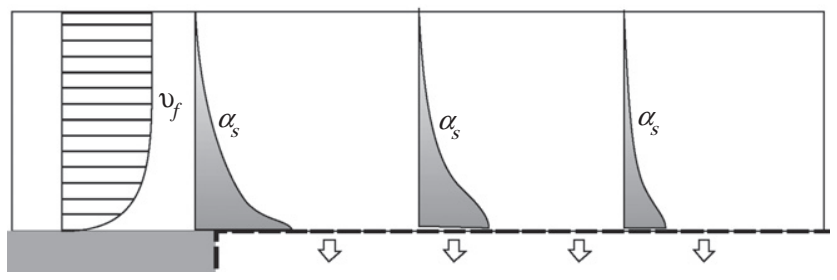

(c) Simple deposition case

Fig. 1. Sketch of physical model. iment phase are set to zero, and the sediment volumetric concentration is given a constant value of 0.6 . In case (iii), a free settling of the sediment particles is considered so that both vertical velocity and the concentration of the sediment phase are assumed to have no gradient in the normal direction.

At the downstream lateral boundary, the flow is assumed to be fully-developed so that the non-gradient condition in the flow direction is valid for all variables. At the upstream lateral boundary, the fully developed condition is applied to the horizontal velocity of the fluid phase and the sediment concentration while the non-gradient condition in the flow direction is applied to the velocity of the sediment phase as well as the variables that characterize the turbulence. The fully developed clear water velocity in case (ii) is given by Dou's (1987) formula:

$\frac{u}{u_{*}}=\frac{1}{K} \ln \left(1+\frac{y^{+}}{5}\right)+7.05\left[\frac{y^{+}}{5+y^{+}}\right]^{2}+2.5\left[\frac{y^{+}}{5+y^{+}}\right]+0.5(1-\cos 2 \pi Y)$

where $u_{*}$ is the shear velocity which can be evaluated from the slope of water surface in a practical problem, $y^{+} \equiv u_{*} y / v_{f 0}$, $Y \equiv y / H$, and $H$ is the water depth. In case (iii), the velocity of the fluid phase at the upstream lateral boundary is also given by Eq. (25) and the sediment concentration is specified according to Van Rijn's (1993) formula with a given rate of sediment transport. There may be some differences between the distributions prescribed by these formulas and the fully developed profiles, but this does not matter because the prescribed distributions will adjust themselves and approach the fully developed profiles at some distance downstream the boundary. In the equilibrium case (i), the inflow condition only requires to ensure a prescribed flow rate. The velocity profile at the boundary is self-adjustable during the computation as time advancing. At each computational step, however, a flux modification of the velocity profiles at both the upstream and downstream boundaries must be done to ensure the inflow condition being satisfied. The modification is actually to remove the error originating from the self-adjustment of the velocity profile by slightly scaling the numerical result. It is significant only at the initial stage of the computation when the fully developed profile is not yet achieved. Eq. (25) and Van Rijn's (1993) formula are utilized to give the initial values of the fluid velocity and the sediment concentration at both the upstream and downstream boundaries.

\section{Model verification for equilibrium transport}

Two types of experimental results are used to verify the performance of the present numerical model for equilibrium transport or under steady-state condition. They are (1) Coleman's (1986) experiment on saturated sediment-laden flows; and (2) Li's (1999) experiment on sediment-laden flows of high concentration. It may be necessary to emphasize that, under all experimental conditions, the erodible bed keeps flat. The computational domain coincides with the experiments. The computational grid size is fixed at $1 \mathrm{~cm}$ in the horizontal direction, while it varies in the vertical direction from $0.01 \mathrm{~cm}$ at the bottom to $0.7 \mathrm{~cm}$ at the surface in Coleman's case and from $0.01 \mathrm{~cm}$ at the bottom to $0.35 \mathrm{~cm}$ at the surface in Li's case. The grid size is determined after a great number of numerical tests. It is proved that any further refinement of the grid leads to no change of the significant digits of the numerical results.

\subsection{Coleman's experiment}

The experiment was conducted in a circulating flume of $15 \mathrm{~m}$ in length and $0.356 \mathrm{~m}$ in width. The flow was generated at the upstream end of the flume at a rate of $0.064 \mathrm{~m}^{3} / \mathrm{s}$, the resulting depth 
Table 1

Coleman's experimental conditions.

\begin{tabular}{llll}
\hline Group & A & B & C \\
\hline Clear water case & Run 1 & Run 21 & Run 32 \\
Saturated case & Run 20 & Run 31 & Run 40 \\
Sediment classification & Fine & Medium & Coarse \\
Sediment diameter $\left(D_{s}\right)$ & $0.105 \mathrm{~mm}$ & $0.21 \mathrm{~mm}$ & $0.42 \mathrm{~mm}$ \\
\hline
\end{tabular}

of the flow was around $0.17 \mathrm{~m}$. The bottom shear velocity computed from the measured slope of the water surface was $0.041 \mathrm{~m} / \mathrm{s}$. Measurement was made in the region of $y \geqslant 0.006 \mathrm{~m}$ on the centerline of the flume at a cross-section located $12 \mathrm{~m}$ away from the upstream end. The sediment density in the experiment was $2650 \mathrm{~kg} / \mathrm{m}^{3}$. Other conditions are summarized in Table 1. Among a total number of 40 runs, Runs 1, 20, 21, 31, 32, and 40, for fine, medium, and coarse sediment, respectively, were carried out under clear water or sediment saturated conditions, and are referred in the present study.

Fig. 2 compares the computed and measured horizontal velocity of the fluid phase. The general agreement between computations and measurements is rather good except for the coarse sediment case (Run 40), in which the computational result is larger than the experimental data at the upper layer but smaller at the lower layer. The inaccuracy is probably a consequence of the simple turbulence model for the sediment phase. By comparing the saturated
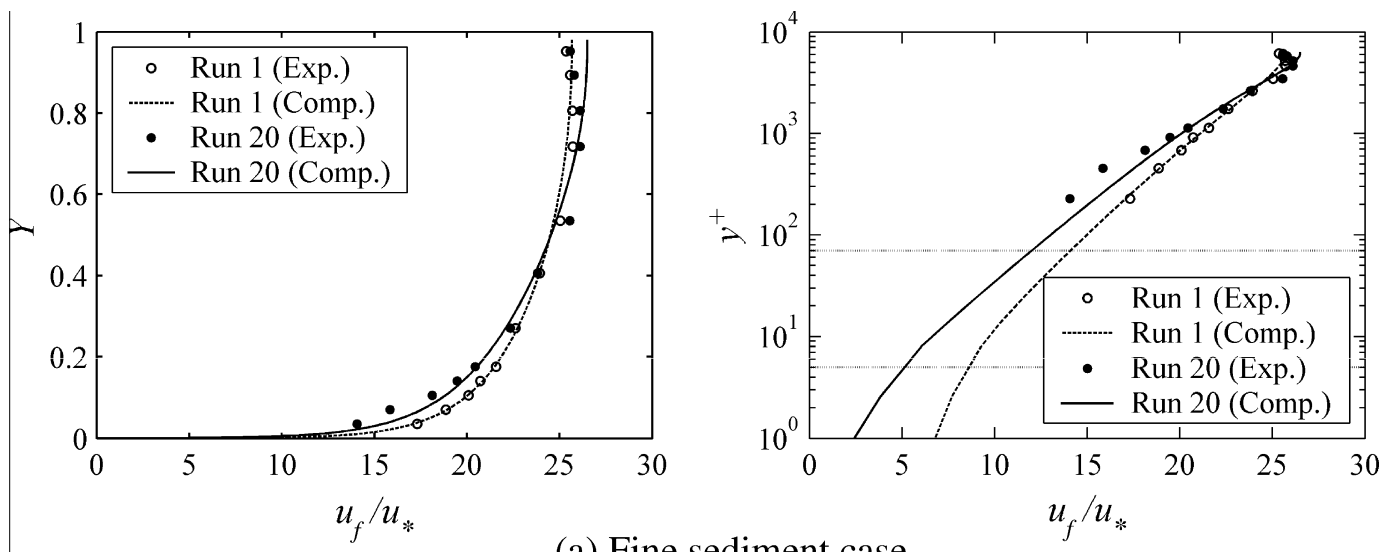

(a) Fine sediment case
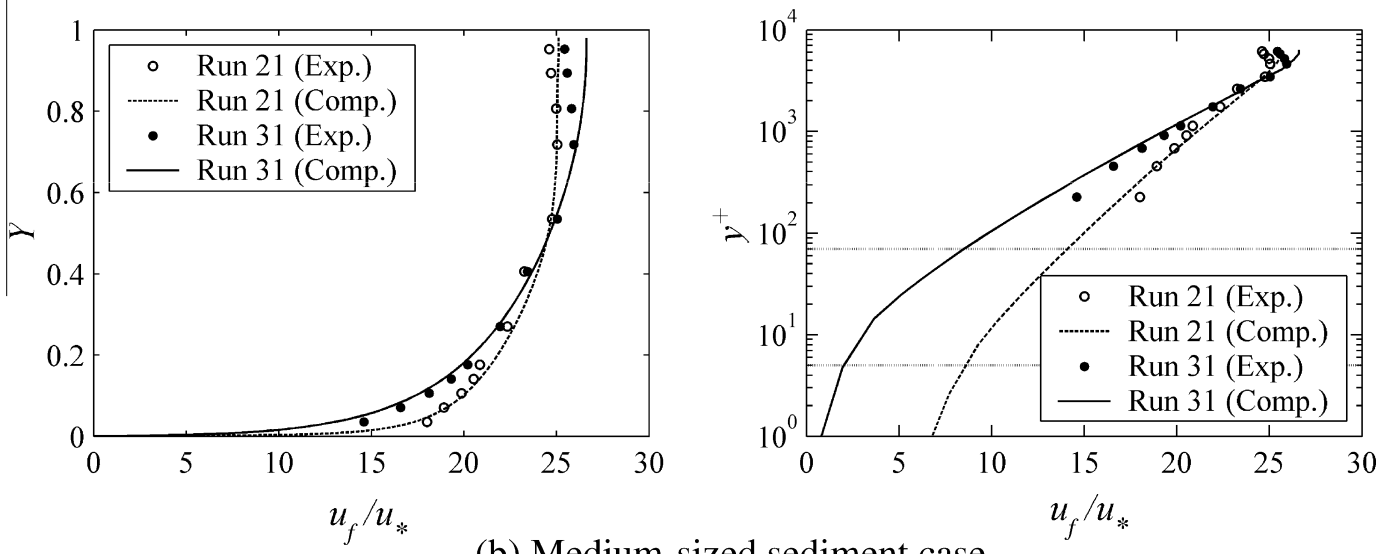

(b) Medium-sized sediment case
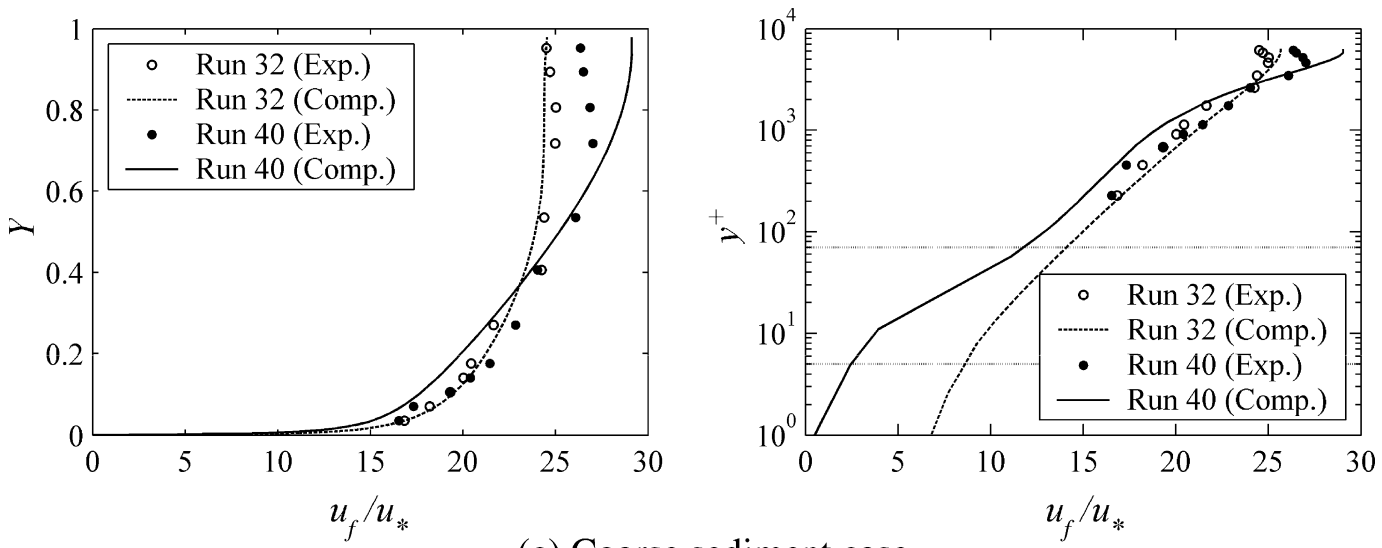

(c) Coarse sediment case

Fig. 2. Horizontal velocity of fluid phase in Coleman's experiments. 
sediment-laden cases with the relevant clear water ones, it is found that the horizontal velocity of the fluid phase decreases near the bottom and increases at the top. The tendency is consistent in both numerical and experimental results and in all cases. Many other studies, such as Wang (1985), also confirmed this fact. This can be explained by the increased bed resistance due to the presence of sediment which reduces the flow velocity at lower level while increases the flow velocity near the water surface to conserve the flux.

Fig. 2 also provides a close view of the computed horizontal velocity of the fluid phase near the bottom boundary by plotting it against $y^{+}$in the logarithmic scale. Two levels corresponding to $y^{+}=5$ and $y^{+}=70$, which are generally regarded as the upper limit of the viscous sublayer and the lower limit the fully-developed turbulent layer of a boundary layer flow of clear water, are also marked in the figures. The computational results show a reasonable agreement with the linear law and the logarithmic law for the velocity near the solid bottom and in the fully-developed turbulent region. Einstein and Chien (1955) proposed to divide the sediment-laden flow into two regions: the bottom flow region and the main flow region. The bottom region refers to the viscous sublayer and the transition layer while the main region is the fullydeveloped turbulent layer. The transition point of the two regions such defined moves upward as the sediment concentration increases according to the experiments of Wang (1985). The same tendency can also be observed in the present computations, as indicated in Fig. 2.

Fig. 3 shows comparison of the computed and measured vertical profile of the saturated sediment volumetric concentration. The agreement between the computation and Coleman's measurement seems to be fairly good. The concentration is shown to decrease quickly to nearly nothing near the free surface from its maximum value at the bottom in all cases. The saturated sediment concentration also decreases as the sediment diameter increases. A close view reveals that, somehow, the computed concentration and the concentration gradient of fine sediment is slightly larger than the experimental results in the main flow region and the computed concentration of coarse sediment is slightly smaller than that in the experiment.

According to Rouse (1937), the saturated sediment profile in a uniform flow is reached when the gravity caused settling and turbulence caused diffusion of the sediment particles are balanced. This implies that the vertical velocity of the sediment phase, at least in the main flow, in Coleman's experiments should be very close to the fall velocity of the sediments. In Fig. 3, the computed vertical velocity of the sediment phase is presented, and the relevant values obtained near the surface are compared with the fall velocity estimated by formulas of Rubey (1993), Van Rijn (1993), Cheng (2001), Chang and Liou (2001) in Table 2. A reasonable agreement of the computational result with the empirical formulas can be observed. This provides an indirect verification of the turbulence model.

\subsection{Li's experiment}

Li's (1999) experiment was aimed to study hyper-concentrated sediment-laden flows. The experiment was conducted in a flume of $0.3 \mathrm{~m}$ wide, $0.4 \mathrm{~m}$ high and $20 \mathrm{~m}$ long. Light sediment with a density of $1.056 \mathrm{~kg} / \mathrm{m}^{3}$ and diameter of $0.1 \mathrm{~mm}$ was utilized. The fall velocity of a single sediment particle is $0.0003 \mathrm{~m} / \mathrm{s}$. The depth-

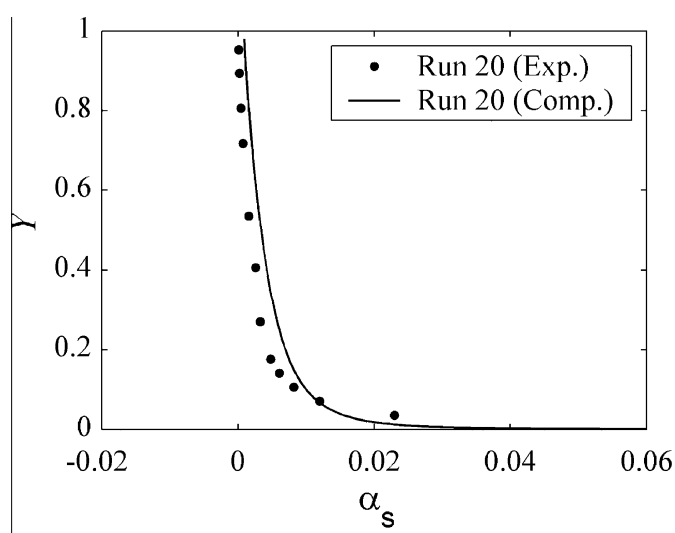

(a) Fine sediment case

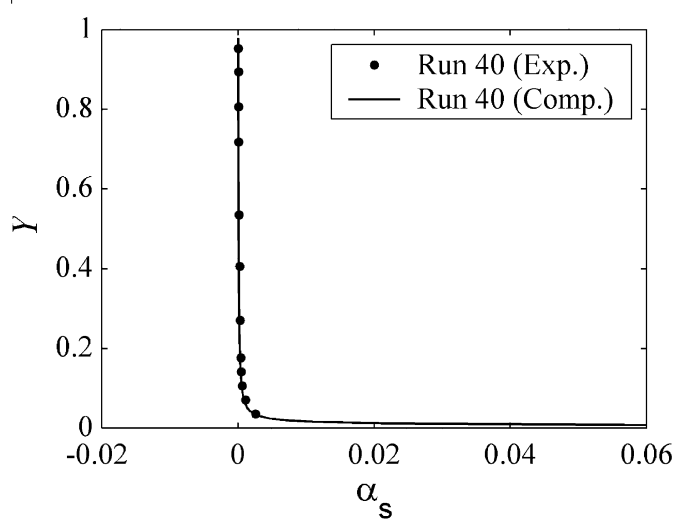

(c) Coarse sediment case

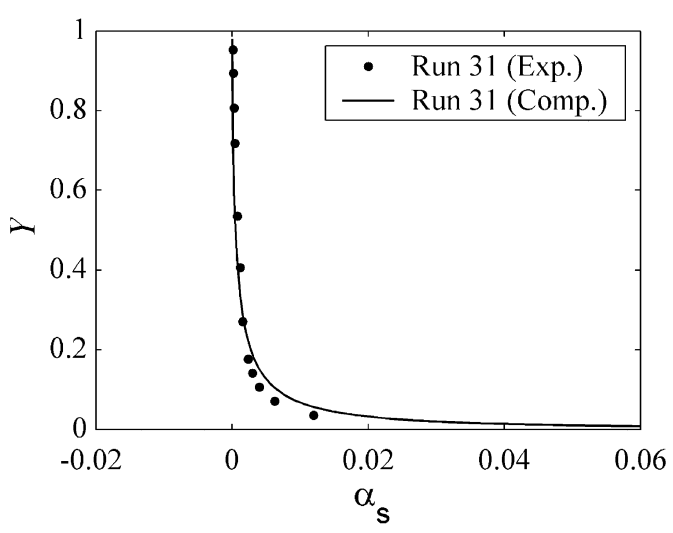

(b) Medium-sized sediment case

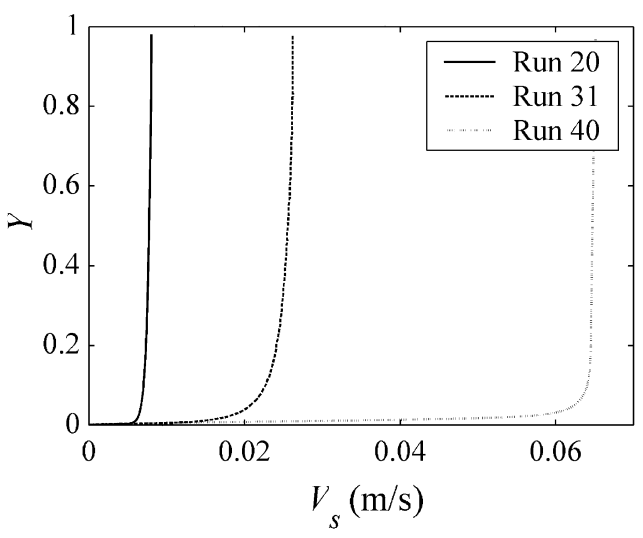

(d) Vertical velocity of sediment phase

Fig. 3. Concentration and vertical velocity of saturated sediment-laden flow. 
Table 2

Sediment fall velocity.

\begin{tabular}{|c|c|c|c|c|c|}
\hline \multirow[t]{2}{*}{ Ds. $(\mathrm{mm})$} & \multirow[t]{2}{*}{ Computational $(\mathrm{m} / \mathrm{s})$} & \multicolumn{4}{|c|}{ Empirical (m/s) } \\
\hline & & Rubey & Van Rijn & Chen & Chang and Liou \\
\hline 0.105 & 0.0083 & 0.0092 & 0.0085 & 0.0066 & 0.0085 \\
\hline 0.210 & 0.0262 & 0.0269 & 0.0276 & 0.0208 & 0.0266 \\
\hline 0.420 & 0.0650 & 0.0545 & 0.0620 & 0.0505 & 0.0637 \\
\hline
\end{tabular}

averaged horizontal velocity in the experiment was $0.781 \mathrm{~m} / \mathrm{s}$ while the water depth was $0.07 \mathrm{~m}$. The bottom shear velocity computed from the measured slope of water surface was $0.037 \mathrm{~m} / \mathrm{s}$. The average volumetric concentration of the sediment in the experiment varied from $0.25 \%$ to $0.5 \%$.

In the computations, the sediment volumetric concentration at the bottom is intentionally specified at different values. Fig. 4a compares the computed horizontal velocity of the sediment phase with the measured data. The computations are made as the average sediment volumetric concentration takes values of $0.25 \%$ and $0.5 \%$. Fig. $4 \mathrm{~b}$ shows the computed horizontal velocity of the fluid phase, in which $0.00 \%$ corresponds to the clear water case. Fig. $4 \mathrm{c}$ shows the computed turbulence kinetic energy (TKE) of the sediment phase, in comparison with the measured data and the empirical formula of Nezu and Rodi (1986) for dilute problems. All the computational results agree very well with the experimental data. The results also imply that, for light and fine sediment, both the Reynolds averaged velocity and the turbulence kinetic energy of the sediment phase are nearly independent on the concentration,

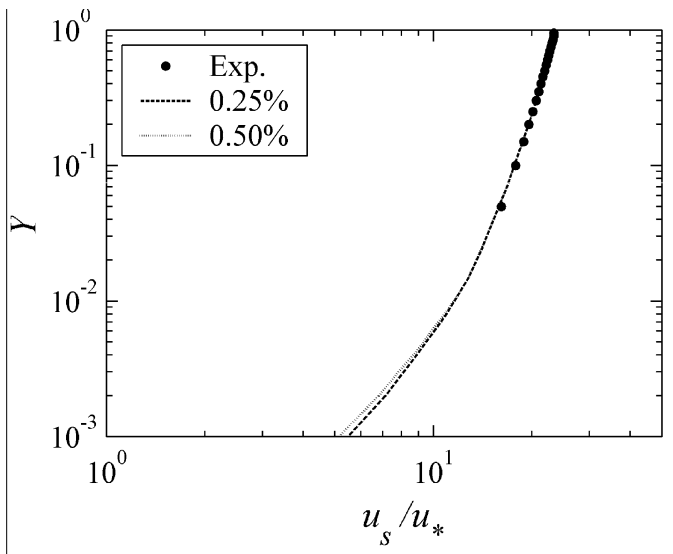

(a) Horizontal velocity of sediment phase

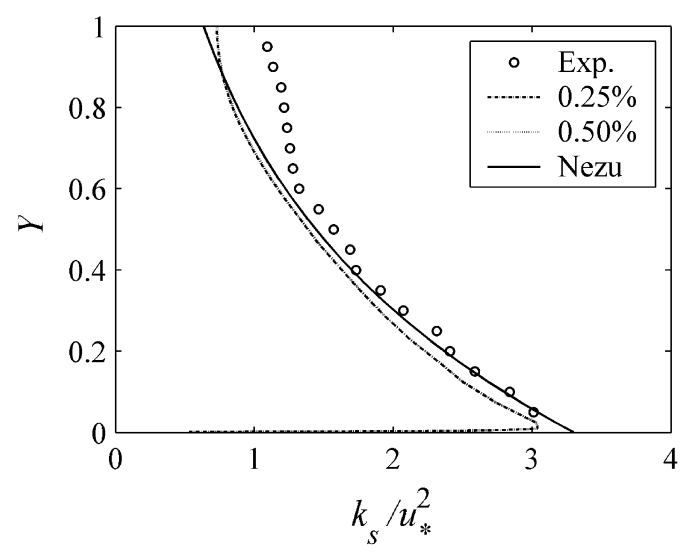

(c) TKE of sediment phase or, the suspended sediment does not change the flow structure significantly, or in other words, the sediment particles trace the fluid flow without a noticeable lag.

It is known that the interaction among sediment particles retards the fall velocity of a single sediment particle. The effect of the sediment concentration on the fall velocity of sediment then cannot be neglected if the sediment concentration is high. Quite a number of studies have been done to investigate the effect of concentration on sediment fall velocity, of which Richardson and Zaki (1954) proposed a formula

$V=\left(1-\alpha_{s}\right)^{m}$

where $V$ is the ratio of sediment fall velocity considering group effects to the fall velocity of a single sediment particle, $m$ is a parameter varying from 2.5 to 7.0 for ordinary sediment depending on the sediment size (Chien and Wan, 1999). It should take a larger value for light sediment. As shown in Fig. 4d, Eq. (26) at $m=8.0$ fits the computational results in a very good accuracy.

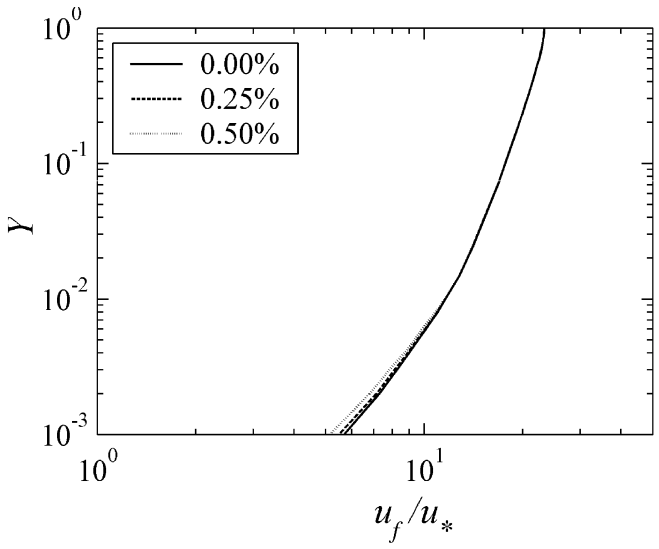

(b) Horizontal velocity of fluid phase

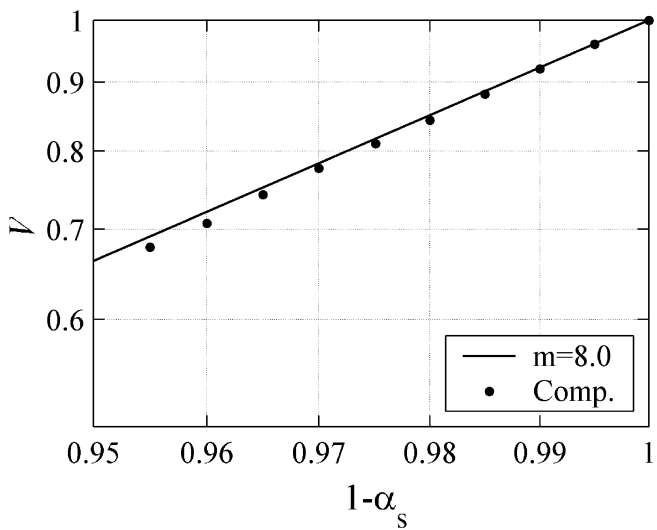

(d) Sediment fall velocity

Fig. 4. Results of hyper-concentrated sediment-laden flow. 


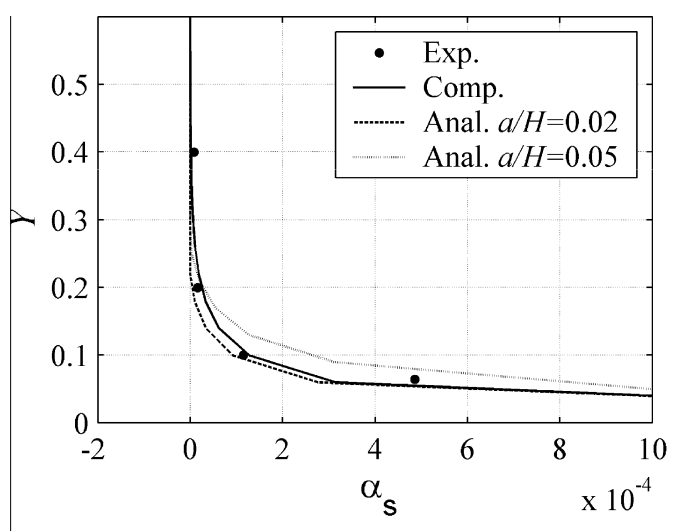

(a) $x / H=4$

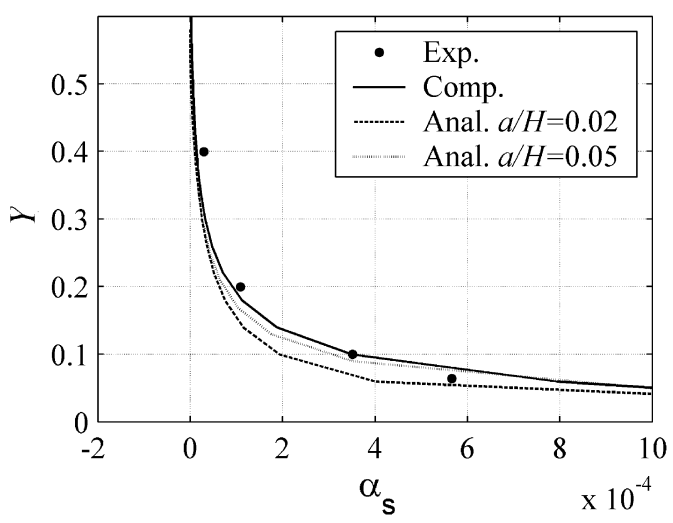

(c) $x / H=20$

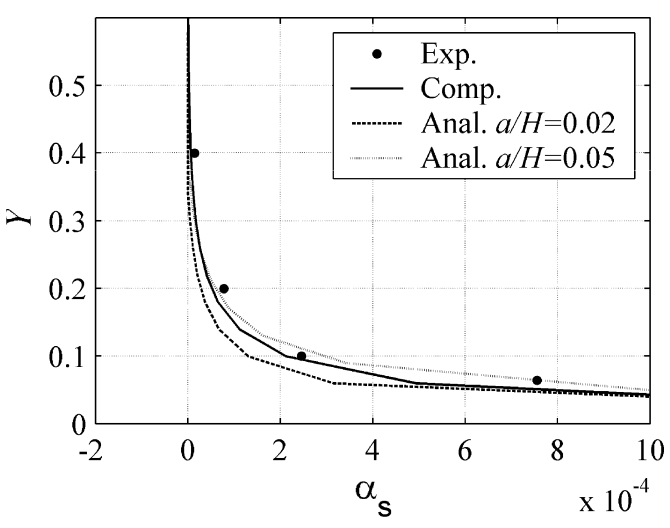

(b) $x / H=10$

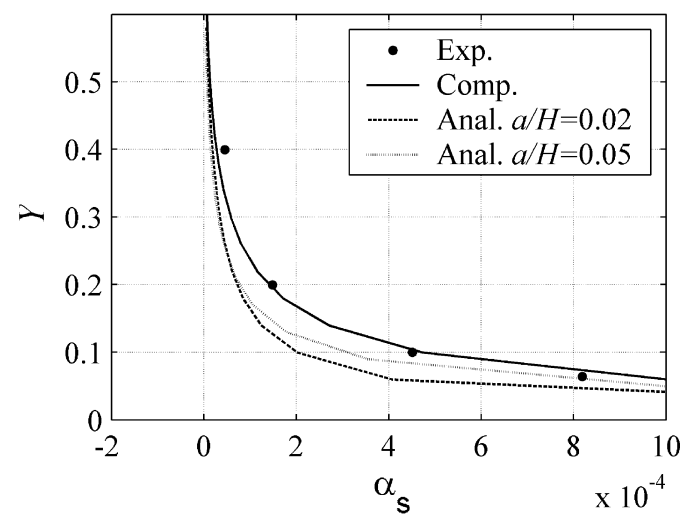

(d) $x / H=40$

Fig. 5. Concentration profile of Van Rijn's experiment.

\section{Model verification for non-equilibrium transport}

Two carefully designed experiments are cited to verify the present numerical model when erosion and deposition occur. The experiments are (1) Van Rijn's (1981) on simple erosion; and (2) Wang and Ribberink's (1986) on simple deposition. Under all experimental conditions the erodible bed was flat. We are going to show that the model we developed also works well for nonequilibrium transport problems. In the following computations, the experimental problems are discretized with a horizontal grid fixed at $5 \mathrm{~cm}$ and vertical grid varying from $0.01 \mathrm{~cm}$ at the bottom to $1.0 \mathrm{~cm}$ at the surface. The accuracy of grid system has been carefully testified.

\subsection{Van Rijn's experiment}

Van Rijn's (1981) experiment was on sediment transport under simple erosion conditions as shown in Fig. $1 \mathrm{~b}$, in which sediment particles are entrained from sandy bed into the water. The wave flume was $30 \mathrm{~m}$ in length, $0.5 \mathrm{~m}$ in width and $0.7 \mathrm{~m}$ in height. In the experiment, the depth-averaged horizontal velocity was $0.67 \mathrm{~m} / \mathrm{s}$; the water depth was $0.25 \mathrm{~m}$ and representative sediment diameter was $0.2 \mathrm{~mm}$. It is worthwhile to mention that Hjelmfelt and Lenau (1970) obtained an analytical solution for the same problem. In the analytic solution, the fall velocity of the sediment is assumed to be a constant $(0.022 \mathrm{~m} / \mathrm{s}$ in the present case), the horizontal diffusion of the sediment is neglected while the vertical diffusion coefficient follows Rouse's (1937) curve that vanishes at the free surface as well as at the bottom.
Fig. 5 shows a comparison among the computational, the experimental and the analytical results on the vertical distribution of the volumetric concentration. The computations agree with the experiments very well. Both indicate that sediment concentration increases in the horizontal direction and it becomes almost saturated at $x / H=40$.

In the analytical solution, the concentration relies on its value at a reference level. For a comparison, two different reference levels are considered, i.e., $a=0.005 \mathrm{~m}(a / H=0.02)$ and $a=0.0125 \mathrm{~m}(a /$ $H=0.05$ ), where concentration are $4.5 \mathrm{~kg} / \mathrm{m}^{3}$ and $2.65 \mathrm{~kg} / \mathrm{m}^{3}$, respectively, according to Lin and Falconer (1997). In either case, the analytical solution does not seem to be as good as the computational results. This is probably because it is not reasonable to assume a constant concentration at any level, for the concentration at the same level in the problem of interest should increase from upstream to downstream.

\subsection{Wang and Ribberink's experiment}

Wang and Ribberink's (1986) experiment was on sediment transport under simple deposition conditions. The experiment was conducted in a flume of $30 \mathrm{~m}$ in length, $0.5 \mathrm{~m}$ in width and $0.215 \mathrm{~m}$ in height. The bed was specially designed to capture the falling sediments. The depth-averaged velocity of the flow was $0.56 \mathrm{~m} / \mathrm{s}$. The bottom shear velocity was $0.033 \mathrm{~m} / \mathrm{s}$. The sediment diameter was $D_{50}=0.095 \mathrm{~mm}$ and $D_{90}=0.105 \mathrm{~mm}$, the density of the sediment was $2650 \mathrm{~kg} / \mathrm{m}^{3}$, and the sediment fall velocity was $0.0071 \mathrm{~m} / \mathrm{s}$.

Fig. 6 shows the computed and the measured concentration profiles at different cross-sections. In the computation, the 


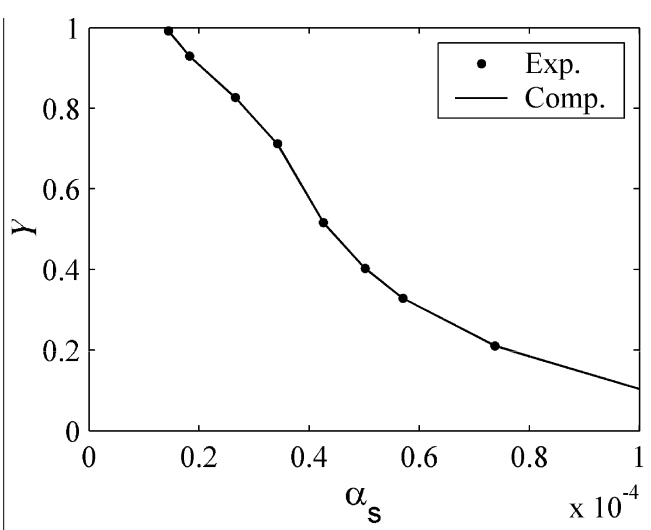

(a) $x / H=0$

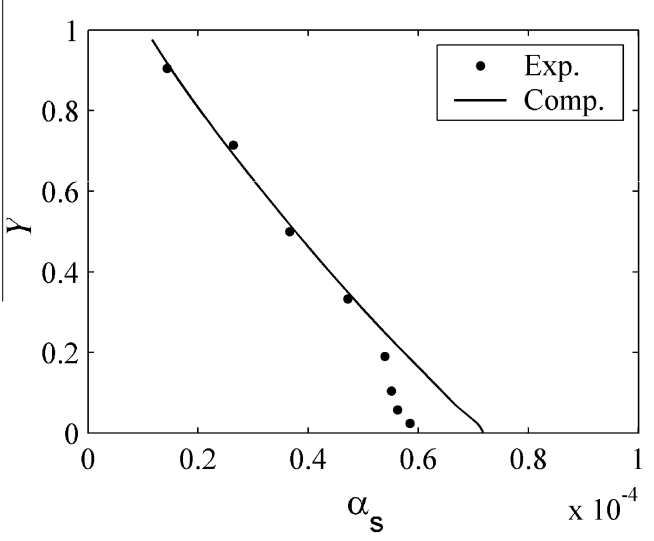

(c) $x / H=9.3$

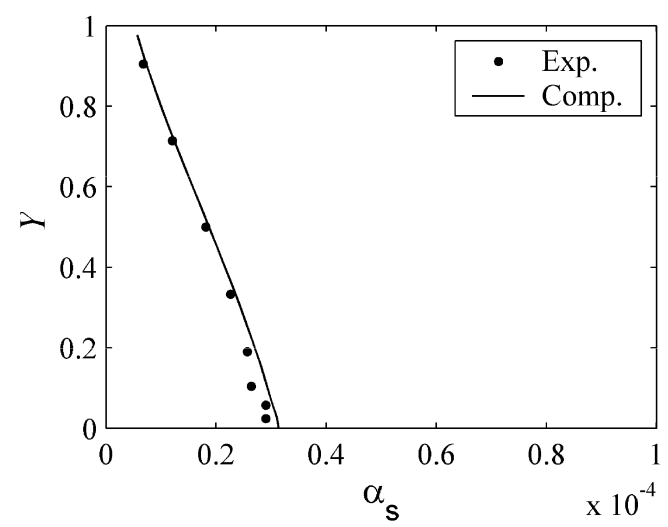

(e) $x / H=37.1$

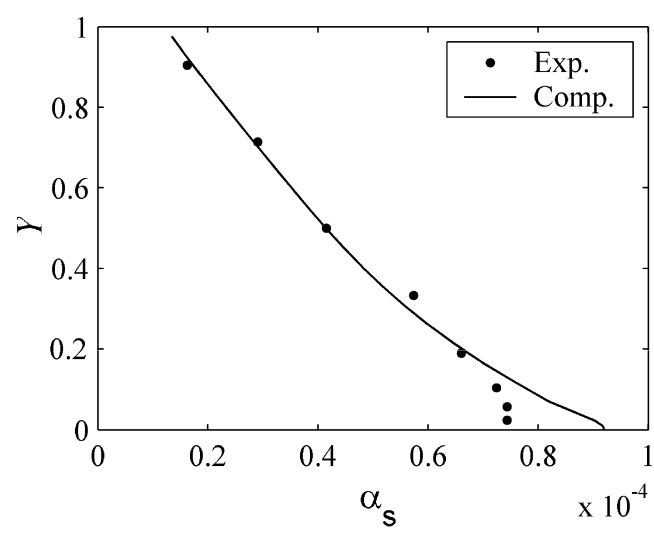

(b) $x / H=4.65$

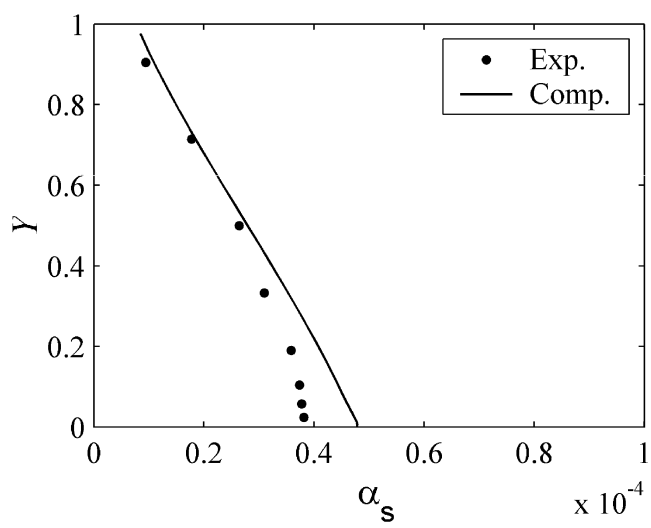

(d) $x / H=20.9$

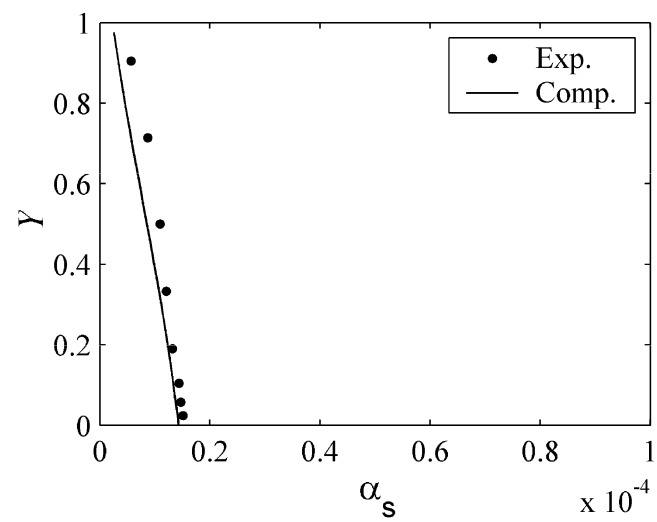

(f) $x / H=74.2$

Fig. 6. Concentration profile of Wang and Ribberink's experiment.

boundary condition for the volumetric concentration of the sediment at $x / H=0$ is given according to the experimental data. The overall agreement between the computations and the experiments is found to be fairly good. Some discrepancy near the bottom is probably because that the bottom boundary conditions of the experiment are not accurately formulated.

\section{Conclusions}

A numerical model for sediment transport is developed based on the basic equations of the two-phase flows. The two phases in the model are coupled through their interaction forces including resistance force, inertia force, and lift force. Turbulence of the continuous phase is described by the conventional $k-\varepsilon$ model while an algebraic particle turbulence model is applied to the dispersed phase. An enhanced algorithm on the basis of the SIMPLE scheme and an effective time stepping technique is developed for the numerical solutions. The model can thus produce numerical results on the temporal and spatial variations of the mean velocities of the two phases as well as the sediment concentration. By involving the inter-granular stress, the model can be applied to sediment transport with high concentration and allows a unified treatment of bed load and suspended load. Because of this, the bottom boundary 
condition can be given at a level beneath the equilibrium bed where the sediment particles are undisturbed and the volumetric concentration of the sediment is totally determined by the natural void of the bed material. Consequently, there is no need to specify the sediment pick-up rate or the concentration at the equilibrium bed. These are the distinguished advantages of the present model when compared to other simplified models.

The two-phase model developed in this study has been applied to the computation of the saturated sediment-laden flow as well as the sediment-laden flows with simple erosion and simple deposition. The numerical results are shown to agree with the available experimental data with a very good accuracy under both equilibrium and non-equilibrium transport conditions.

It is also confirmed in the present study that the horizontal velocity of the fluid phase in a saturated sediment-laden flow decreases near the bottom and increases at the top as compared to the relevant clear water case under given flow discharge. The thickness of the bottom affected flow region in a saturated sediment-laden flow is found to increase as the sediment concentration increases. It is also clear that the computed concentration and the concentration gradient of fine sediment are slightly larger than the experimental results in the main flow region and the computed concentration of coarse sediment is slightly smaller than the experimental results.

\section{Acknowledgments}

This work was partially supported by State Key Laboratory of Hydroscience and Engineering, MOST, China under Grant No. 2011-KY-1 and by Natural Science Foundation of China (NSFC) under Grant No. 10772099. The first author also thanks China Scholarship Council (CSC) for providing him an opportunity to visit School of Engineering, University of Liverpool, UK for 1 year, and he would also like to thank Mrs. Martin Grace at University of Liverpool for her kind help during his stay in UK.

\section{References}

Ahilan, R.V., Sleath, J., 1987. Sediment transport in oscillatory flow over flat beds. J. Hydraul. Eng. 113, 308-322.

Auton, T.R., 1987. The lift force on a spherical body in rotational flow. J. Fluid Mech. $183,199-218$

Auton, T.R., Hunt, J.C.R., Prud'homme, M., 1988. The force exerted on a body in inviscid unsteady non-uniform rotational flow. J. Fluid Mech. 197, 241-257.

Bakhtyar, R., Yeganeh-Bakhtiary, A., Barry, D.A., Ghaheri, A., 2009. Two-phase hydrodynamic and sediment transport modeling of wave-generated sheet flow. Adv. Water Res. 32, 1267-1283.

Cao, Z., Wei, L., Jainheng, X., 1995. Sediment-laden flow in open channels from twophase flow viewpoint. J. Hydraul. Eng. ASCE 121, 725-735.

Celik, I., Rodi, W., 1988. Modeling suspended sediment transport in nonequilibrium situations. J. Hydraul. Eng. ASCE 114, 1157-1191.

Chang, H.K., Liou, J.C., 2001. Discussion on a fall-velocity equation by Ahrens. J. Waterw., Port, Coast. Ocean Eng. ASCE 129, 146-150.

Chapalain, G., Thais, L., 2000. Tide, turbulence and suspended sediment modelling in the eastern English Channel. Coast. Eng. 41, 295-316.

Cheng, N., 2001. Discussion on a fall-velocity equation by Ahrens. J. Waterw., Port, Coast. Ocean Eng. ASCE 127, 250-251.

Chien, N., Wan, Z., 1999. Mechanics of Sediment Transport. ASCE Press.

Coleman, N.L., 1986. Effects of suspended sediment on the open-channel velocity distribution. Water Resour. Res. 22, 1377-1384.

Dobbins, W.E., 1943. Effect of turbulence on sedimentation. Trans. Am. Soc. Civil Eng. 109, 262-656.

Dou, G., 1987. Turbulence II. Higher Education Press (in Chinese).

Douillet, P., Ouillon, S., Cordier, E., 2001. A numerical model for fine suspended sediment transport in the southwest lagoon of New Caledonia. Coral Reefs 20, 361-372.

Drew, D.A., 1971. Average field equations for two-phase media. Stud. Appl. Math. 50, 133-166.

Drew, D.A., 1983. Mathematical modeling of two-phase flow. Ann. Rev. Fluid Mech. 15, 261-291.
Einstein, H.A., Chien, N., 1955. Effects of sediment concentration near the bed on the velocity and sediment distribution. Tech. Rep. Inst. Eng. Res. Univ. of California at Berkeley.

Elghobashi, S., Abou-Arab, T.W., 1983. A two-equation turbulence model for twophase flows. Phys. Fluids 26, 931-938.

Fang, H.-W., Wang, G.Q., 2000. Three-dimensional mathematical model of suspended-sediment transport. J. Hydraul. Eng. ASCE 126, 578-592.

Greimann, B.P., Holly, F.M., 2001. Two-phase flow analysis of concentration profiles. J. Hydraul. Eng. ASCE 127, 753-762.

Hayase, T., Humphrey, J.A., Grif, R., 1992. A consistently formulated QUICK scheme for fast and stable convergence using finite-volume iterative calculation procedures. J. Comput. Phys. 98, 108-118.

Hinze, J.O., 1975. Turbulence. McGraw-Hill.

Hjelmfelt, A.T., Lenau, C.W., 1970. Nonequilibrium transport of suspended sediment. J. Hydraul. Div. ASCE 96, 1567-1586.

Hsu, T., Jenkins, J.T., Liu, P., 2004. On two-phase sediment transport: sheet flow of massive particles. Proc. Roy. Soc. Lond. A460, 2223-2250.

Ishii, M., Hibiki, T., 2006. Thermo-Fluid Dynamics of Two-Phase Flow. Springer.

Jha, S.K., Bombardelli, F.A., 2009. Two-phase modeling of turbulence in dilute sediment-laden, open-channel flows. Environ. Fluid Mech. 9, 237-266.

Jha, S.K., Bombardelli, F.A., 2010. Toward two-phase flow modelling of non-dilute sediment transport in open channels. J. Geophys. Res. 115, F03015.

Kobayashi, N., Seo, S.N., 1985. Fluid and sediment interaction over a plane bed. J. Hydraul. Eng. ASCE 111, 903-921.

Li, D., 1999. Study on Characteristics of Suspended Particles. PhD Thesis, Dept. Hydr Engrg., Tsinghua Univ. (in Chinese).

Lin, B., Falconer, R., 1997. Numerical modeling of three-dimensional suspended sediment for estuarine and coastal water. J. Hydraul. Res. 34, 435-456.

Lin, B.N., Huan, J.Q., Li, X.Q., 1983. Unsteady transport of suspended load at small concentrations. J. Hydraul. Eng. ASCE 109, 86-98.

Longo, S., 2005. Two-phase flow modeling of sediment motion in sheet-flows above plane beds. J. Hydraul. Eng. 131, 366-379.

McTigue, D.F., 1981. Mixture theory for suspended sediment transport. J. Hydraul. Div. ASCE 107, 659-673.

Miller, H.P., 1983. Three-dimensional free-surface suspended particle transport in the south Biscayne bay, Florida. Int. J. Numer. Methods Fluids 4, 901-914

Nezu, I., Rodi, W., 1986. Open-channel flow measurements with a laser-Doppler anemometer. J. Hydraul. Eng. 112, 335-355.

O'Brien, M.P., 1933. Review of the theory of turbulent flow and its relation to sediment transport. Trans. Am. Geophys. Union, 481-491.

O'Connor, B.A., Nicholson, J., 1988. A three-dimensional model of suspended particulate sediment transport. Coast. Eng. 12, 157-174.

Pai, S.I., 1991. Fundamental equations of a mixing of a gas and small spherical solid particles from kinetic theory. J. Math. Phys. Sci., l-15.

Patankar, S.V., 1980. Numerical Heat Transfer and Fluid Flow. Hemispher Publishing Corp..

Peker, S.M., Helvaci, S.S., 2008. Solid-Liquid Two Phase Flow. Elsevier.

Richardson, J.F., Zaki, W.N., 1954. Sedimentation and fluidization (Part 1). Trans. IChE 32, 35-53.

Rouse, H., 1937. Modern conceptions of the mechanics of turbulence. Trans. ASCE 102, 436-505.

Rubey, W.W., 1993. Settling velocities of gravel, sand and silt particles. Am. J. Sci. 25 325-338.

Schiller, L., Naumann, A., 1935. A drag coefficient correlation. Z. Ver. Deutsch. Ing. $77,318$.

Spalding, D.B., 1985. Computer simulation of two-phase flows, with special reference to nuclear-reactor system. In: Lewis, R.W., Morgan, K., Johnson, J.A (Eds.), Computational Techniques in Heat Transfer. Pineridge Press, 1-44.

Tam, C.K.W., 1969. The drag on a cloud of spherical particles in low Reynolds number flow. J. Fluid Mech. 38, 537-546.

Tao, W., 2001. Numerical Heat Transfer. Xi'an Jiaotong University Press (in Chinese).

Ungarish, M., 1993. Hydrodynamics of Suspensions: Fundamentals of Centrifugal and Gravity Separation. Springer.

Van Rijn, L.C. 1981. Entrainment of fine sediment particles: development of concentration profiles in a steady, uniform flow without initial sediment load. Rep. No. M1531, Part II, Delft Hydraulic Laboratory, Delft, Netherlands.

Van Rijn, L.C., 1993. Principles of Sediment Transport in Rivers. Estuaries and Coastal Seas. Springer.

Wang, X. (1985). The Motion of Suspended-Load and Its Effects on the Structure of Flow. PhD Thesis, Dept. Hydr. Engrg., Tsinghua Univ. (in Chinese).

Wang, Z.B., Ribberink, J.S., 1986. The validity of a depth-integrated model for suspended sediment transport. J. Hydraul. Res. 24, 53-63.

Wörner, M., 2003. A compact introduction to the numerical modeling of multiphase flows. Forschungszentrum Karlsruhe GmbH. Karlsruhe, Germany.

Wu, W., Rodi, W., Wenka, T., 2000. 3D numerical modeling of flow and sediment transport in open channels. J. Hydraul. Eng. ASCE 126, 4-15.

Zhou, J.J., Lin, B.N., 1998. One-dimensional mathematical model for suspended sediment by lateral integration. J. Hydraul. Eng. ASCE 124, 712-717.

Zuber, N., Findlay, J.A., 1965. Average volumetric concentration in two-phase flow systems. J. Heat Trans. 87, 453-468. 